\title{
Research on the Mode and Path of Industrial Upgrading of Shandong Agricultural Science and Technology Park
}

\author{
Zhao Hua \\ Shandong Xiehe University \\ Shandong, Jinan, 250000, China
}

\begin{abstract}
Agricultural science and technology parks, which gather many elements of modern agricultural production, play an important role in improving the utilization of resources, promoting the transformation of agricultural management and improving the quality of rural economic development. This paper takes the agricultural science and technology park of Shandong Province as the research object, used field investigation and other methods to collect and analyze, combined with the specific situation of Shandong province, to provide more theoretical and technical support for the scientific planning of agricultural parks and the standardization of Park construction, and to form a more scientific and effective technical support system through the exploration of efficient land use, industrial upgrading mode and so on in agricultural parks.
\end{abstract}

Keywords-agricultural parks; industrial upgrading; development path; innovation mechanism

\section{INTRODUCTION}

In recent years, the research on agricultural parks in China has emerged with the upsurge of Park construction. The research mainly focuses on the following aspects: One is the planning and construction of the park, such as the construction of the core area, demonstration zone and radiation zone; the second is the study of the status and development model of land use in the park, including land intensive and different utilization modes; the third is the study on relationship between land use and industrial structure, such as the location of agricultural high-tech demonstration park, industrial positioning, land use planning and demonstration leading role; the fourth is to study the land management mechanism of the park and establish a long-term and effective park planning and supervision and inspection mechanism [1]; the fifth is the evaluation of the land use efficiency of the park[2], and the evaluation index system is constructed from the multi-faceted perspective of the comprehensive benefits of the park development. The above research and design scope is wider, but the depth is slightly inadequate. There is also a lack of pertinence specific to every place.

\section{DeVelopment Status of Shandong AgRicultural SCIENCE AND TECHNOLOGY PARK}

Shandong Province is a large agricultural province. The natural resources endowment conditions and social and

Key Soft Science Project of Shandong Province: Innovation Mechanism and Development Model of Shandong Agricultural Science and Technology Park, Project Number: 2018RZB01121 economic development degree differs in different regions. There are many kinds of agricultural science and technology parks, and the specific development models vary widely. Based on the survey on the geographical region and industrial characteristics of Shandong Agricultural Science and Technology Park, the following characteristics are shown:

\section{A. Large number of modern agricultural parks and wide geographical distribution}

As a major agricultural province, Shandong Province has been in a leading position in agricultural development. By the end of 2016, the Shandong provincial government has approved the construction of 12 provincial agricultural hightech development zones. Among them, the Yellow River delta agricultural high tech industry demonstration area has become the second country's high agricultural area in China. In 2017, the provincial government approved the establishment of two provincial-level agricultural high-tech industrial development zones, namely, the Longkou Provincial Agricultural High-tech Industrial Development Zone with a planned area of 10.91 square kilometers and the Qingdao West Coast Provincial Agricultural High-tech Industrial Development Zone with a planned area of 2.37 square kilometers. During the 13th FiveYear Plan period, Shandong Province will strive to build 1-2 new national agricultural high-tech industrial development zones, 10 or so state-level agricultural science and technology parks, 20 or so new provincial high agricultural areas, standardize and upgrade the development level of provincial agricultural science and technology parks in the areas of characteristic fruit, seawater agriculture and marine aquaculture.

\section{B. A Variety of Agricultural Science and Technology Parks}

The classification of agricultural science and Technology Parks in Shandong Province is diversified, as shown in TABLE I. 
TABLE I.

Classification of Shandong agricultural science and Technology Park

\begin{tabular}{|c|c|c|}
\hline Division method & Park type & Examples \\
\hline Investment subject & $\begin{array}{c}\text { A park built by the government, a park built by a scientific } \\
\text { research institution, a park built by an enterprise, and a joint } \\
\text { venture construction Park }\end{array}$ & $\begin{array}{l}\text { The Yellow River delta agricultural high tech Industrial Park, } \\
\text { Huasheng green Chengwu photovoltaic agricultural science and } \\
\text { technology demonstration Industrial Park }\end{array}$ \\
\hline Administrative level & National, provincial and municipal level & $\begin{array}{c}\text { Shandong Shouguang agricultural science and Technology Park, } \\
\text { Qingdao West Coast provincial agricultural high tech Industrial } \\
\text { Development Zone and so on }\end{array}$ \\
\hline Industrial characteristics & $\begin{array}{c}\text { Deep processing agricultural park, suburban agricultural park, } \\
\text { characteristic agricultural park and comprehensive opening } \\
\text { park }\end{array}$ & $\begin{array}{l}\text { Weihaina Xiangshan agricultural science and technology } \\
\text { demonstration park, etc. }\end{array}$ \\
\hline $\begin{array}{l}\text { Technology content and } \\
\text { driving capacity }\end{array}$ & $\begin{array}{c}\text { High-tech park, technology development park, achievement } \\
\text { incubator park, technology popularization and popularization } \\
\text { Park }\end{array}$ & $\begin{array}{l}\text { Qingdao Agricultural University modern agricultural science and } \\
\text { technology demonstration garden, etc. }\end{array}$ \\
\hline
\end{tabular}

The above is the general classification of Shandong agricultural science and technology park. Shandong Agricultural Science and Technology Park, Agricultural Hitech Industrial Development Zone and Modern Agricultural Park are relatively large in number. In the classification, it is inevitable that an agricultural industrial park has multiple identities.

\section{Technology intensive, but intensive input and output imbalance}

As modern agricultural science and technology parks generally shoulder the mission of demonstration, extension, blessing and promotion of modern agriculture development. Therefore, the development of agricultural science and Technology Parks in Shandong Province should be different from that of conventional agricultural parks, which need intensive investment of high-tech, scientific and technological personnel, modern facilities and other elements. Based on the investigation, some areas such as Heze Huasheng Green Energy Chengwu Photovoltaic Agricultural Science and Technology Demonstration Industrial Park, including 362 photovoltaic agricultural science and technology greenhouses and supporting facilities, mainly plant icy grass and other special vegetables. The modern agricultural science and technology demonstration garden of Qingdao Agricultural University is a combination of agricultural scientific research, practical teaching, results incubation, variety display and technological innovation, but its output is not satisfactory.

\section{Characteristics of Land Use}

Shandong Agricultural Science and Technology Park has relatively stable land management rights in a certain area, which provides the basic conditions for the efficient use and development of land and is conducive to intensive input of production factors such as technology, capital, labor force and large-scale operation of agriculture. Intensive land input is prominent, and most parks enjoy preferential policies and mechanisms. However, the utilization rate of high-tech facilities varies greatly among the parks, which is affected by the fluctuation of agricultural products market, investment and operation mode and other factors. Some parks do not bring high returns because of high investment. The overall efficiency of land use in the parks is not high, and the efficiency gap is wide.

\section{Problem ANALysis of Shandong Agricultural SCIENCE AND TECHNOLOGY PARK}

\section{A. Urbanization and Similarization of the Park}

The development of agricultural parks should have its own characteristics, and the growth of agricultural products should be restricted by certain natural laws. Compared with industrial parks, the production of agricultural parks is a process of interweaving natural reproduction with economic reproduction. By means of input, technology and facilities, the production conditions of agricultural parks can be changed, and the productivity and efficiency of agricultural production in the parks can be improved[3]. Through visiting many agricultural parks in Shandong Province, the author finds that most of them apply the ideas and methods of urban planning system in construction planning, pays more attention to the "high, big and noble" construction of the park, the high input of facilities and equipment, and the high input of agricultural production, but neglects the natural law and the economic law of agricultural production that must be followed in the growth of agricultural products. As a result, a number of "agricultural eco-parks" with great similarities and minor differences have been formed in all parts of the province. The parks are similar in operation and the input of factors is high, which often lead to the breakdown of the capital chain and the lack of follow-up investment in the later period and eventually nothing.

\section{B. Lack of Overall Management in the Park Construction, Evaluation and Supervision Mechanism}

At present, in the construction of agricultural parks in Shandong Province, there is a phenomenon of "only in" and "out of" one mode, all over the country have mounted and blossomed everywhere, but the quality of operation and management is not high. Agricultural industrial parks in various cities are rebuilt with less management, and formalism is serious. They are just image projects, without actual landing, not to mention the real output of benefits, demonstration and promotion. In addition, in the evaluation of the park, it is not enough to only look at the number of agricultural science and Technology Parks in a certain area and the output of the park benefits reported. The law of the market is survival of the fittest, and only when there is entry and exit can it conforms to the natural law. Therefore, after the completion of the park, the evaluation and supervision mechanism needs to be strengthened so as to better serve the sustainable development of the local agricultural science and technology park. 


\section{Loose Combination of Production, Teaching and Research and Insufficient Ability of Innovation}

For agricultural science and technology parks, production, teaching and research mainly refers to the integration of agricultural science and technology innovation, science and technology promotion and technology transformation. Only when an agricultural scientific and technological innovation activity is transformed into actual productive forces and more industrial value is created, can it be regarded as an effective scientific and technological innovation. At present, the status of agricultural industry in Shandong Province is analyzed, such as Shandong Agricultural University, research institutions such as the Academy of Agricultural Sciences, but as far as the investigation is concerned, the strength of relevant scientific research institutions is still relatively weak, unable to track and understand each industrial park. At present, the agricultural science and Technology Parks in all parts of the country generally have the phenomena of small number of agricultural science and technology personnel and unreasonable technical structure, which can not meet the requirements of the development of high-tech agriculture. In June 2018, the Shandong Provincial Science and Technology Department studied and formulated the Shandong Province Enterprise Science and Technology Commissioner thousand people to serve thousands of enterprises "three-year action plan. The effect remains to be further observed.

\section{Imbalance of Spatial Allocation Structure for Efficient Land Use in Parks}

At present, the land planning of Shandong Agricultural Park lacks the idea of efficient utilization as the starting point, aiming at the intensive input of various factors and the ultimate economic indicators. As a result, the agricultural science and technology parks are unreasonable in construction planning and layout, resulting in the imbalance of land structure in spatial allocation. The park planning is always pursuing the big and the whole, rather than seeking the suitable planning from the reality. In terms of facilities and facilities, the park considers that the adoption of high technology will bring about results. They have invested intensively in the construction of "core areas" which are not closely related to the park industry, and "eco-catering" and "self-harvesting" are everywhere, which leads to inefficiently structure and layout of land, unreasonable structure of land allocation, decrease of quality of land in the park, land output and benefits.

\section{COUNTERMEASURES FOR INDUSTRIAL UPGRADING OF SHANDONG AGRICULTURAL SCIENCE AND TECHNOLOGY PARK}

\section{A. Adjust the Development Mode of Different Parks According to Local Conditions}

According to the characteristics of agricultural development in different areas of Shandong Province, the agricultural science and Technology Parks in Shandong Province are divided into six different development modes, as shown in Fig. 1 .

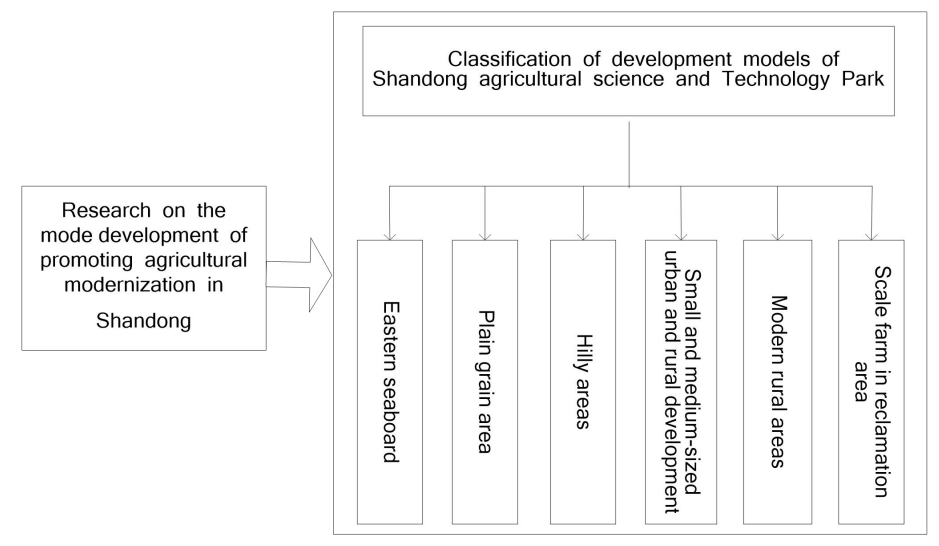

Fig. 1. Classification of Development Models of Agricultural Science and Technology Parks in Shandong Province

The above chart classifies all the cities in Shandong province according to their geographical characteristics. For example, the eastern coastal areas such as Qingdao, Yantai and Weihai can focus on the development of marine industries, combined with their own characteristics such as Qixia apple and other ancillary development. Since the urban and rural coordinating department is relatively close to the urban area, it can set up some experimental bases, do a good job in agricultural scientific research, develop modern agricultural and ecological parks in the suburbs, promote the local economic development, and adopt a variety of ways, such as contracting system. Finally, in a wider area of cultivated land, modern farms can be planned to reduce production costs by making use of their economies of scale, so that the output of benefits is more significant.

\section{B. Strengthen Government Supervision and Make Macro Planning}

The construction of agricultural science and technology park is to solve the problems of agriculture, countryside and farmers, not to follow the trend of the times. Therefore, we must make overall planning in the planning and construction of the park. We should strengthen the macro-management of the development and construction of agricultural high-tech parks, control the quantity, improve the quality, avoid the excessive and excessive number of parks, and ensure the healthy, rational and orderly development of agricultural high-tech parks. In addition, the park's functions should be reasonably positioned. The examination and approval of the parks are based on scientific proof. The original intention of the establishment of the agricultural science and technology parks is not to engage in image projects, to do real work, to drive the local farmers to become rich and to promote the adjustment of agricultural and rural industrial structure. In the planning and construction of agricultural science and technology parks, the following principles should be adhered to: first, make a breakthrough according to the local characteristics to avoid duplicate construction of the park; second, give full play to regional advantages and determine the structural characteristics of local agricultural production and regional development pattern around regional advantages; third, strengthen the management of the park, improve the evaluation mechanism, so that the development of the park can benefit one side. 


\section{Enhance the Collaborative Innovation Ability of the Park and Pay Attention to Personnel Training}

In view of the unbalanced innovation ability of agricultural science and Technology Parks in Shandong Province, the cooperative innovation of agricultural science and technology parks is put forward to pave the way for the formation of an innovative development pattern with complementary advantages and mutual benefit. Based on the park, the agricultural science and Technology Park focuses on scientific and technological innovation in the fields of seed and seedling industry, modern logistics and preservation of agricultural products, facility planting, healthy livestock and poultry breeding, modern fisheries, water resources utilization and urban leisure and sightseeing agriculture. According to the situation of agricultural scientific and technological resources in Shandong Province, we should give full play to the scientific and technological advantages of agricultural scientific research institutions, optimize the allocation of existing agricultural scientific and technological resources, integrate innovative resources in the park, promote intensive agricultural scientific research, realize the co-construction and sharing of scientific and technological resources and improve the cooperative mechanism in Shandong agricultural science and technology park[4]. Besides innovation, we should also strengthen the introduction and training of agricultural scientific and technological talents, create a working environment and living environment to attract talented people through the construction of laboratories and experimental bases and the reform of management and operation mechanisms. In terms of training, school-enterprise cooperation should be strengthened, agricultural science and technology personnel should be trained through multi-channel cultivation, and the overall quality of agricultural science and technology park should be improved.

\section{Strengthen the Efficient Use of Land in Agricultural Parks}

The main reason for restricting the efficient use of land in the park is that the park lacks overall planning, unclear development target positioning and unable to form its own leading products. Besides, its scale efficiency is low, and it does not play the advantage of large-scale utilization. In addition, the input level of factors will also affect the efficiency of land use in the park, and insufficient or excessive input in the park will lead to the decline of overall efficiency[5]. In order to make efficient use of the land in the park, we can rationally allocate resources, orientate the industry, optimize the land in the park, and explore an industrial system to enhance the land use efficiency by utilizing the spatial distribution and industrial structure. For example: from the spatial point of view, we can refer to the three-dimensional planting mode and strengthens its use efficiency as much as possible from the space volume; in time, the mixed planting mode can be adopted, and the difference of planting time between different crops can be reasonably used for mixed planting, so as to achieve efficient utilization.

\section{CONCLUSION:}

Modern agricultural development has changed from production-oriented to market-oriented, from extensive to intensive and from quantitative to qualitative. As a major agricultural province, Shandong Province has a long way to go in building agricultural science and technology parks. Due to different natural endowments of different regions in Shandong Province, unbalanced regional economic development and different development stages of each park. Based on the principle of adapting measures to local conditions and adopting different development strategies according to the characteristics of different regions in Shandong Province, the development of Shandong Agricultural Science and Technology Park will be more targeted.

\section{REFERENCES}

[1] Liu Kefei. Research on the Mechanism of Scientific and Technological Innovation on Agricultural Industrialization and Modernization [J]. Scientific Management Research, 2015, (01):88-91.

[2] Fu Jianxiang \& Luo Hui. Comprehensive evaluation of modern agricultural demonstration parks in China $[\mathrm{J}]$. Journal of Northwest A\&F University (Social Science Edition). 2017(04): 58-63.

[3] Li Tongsheng \& Luo Yali. Technology Diffusion in Agricultural Science and Technology Parks [J]. Geography Research. 2016(03): 7174.

[4] Wang Yapeng, Lu Ming \& Fan Junnan. Construction of Modern Agricultural Science and Technology Innovation System in China: Characteristics, Realistic Dilemma and Optimization Path[J]. Agricultural Modernization Research, 2015, 36(2): 162-167.

[5] Jiang Fengwu. Optimization of the construction model and countermeasures of the national agricultural science and technology park in Zhangzhou [J]. Farm staff. 2018 (07): 54-56 